\title{
ALTERAÇÕES EM VARIÁVEIS AGROMETEOROLÓGICAS PELO USO DE ESTUFA PLÁSTICA
}

\author{
Reginaldo Ferreira Santos \\ Marcio Antonio Vilas Boas \\ Centro de Ciências Exatas e Tecnológicas, Universidade Estadual do Oeste do Paraná, CP 711, \\ CEP 858114-110, Cascavel-PR, Fone: (0xx45) 220-3155,E-mail:rfsantos@unioeste.br \\ Antonio Evaldo Klar \\ Departamento de Engenharia Rural, Faculdade de Ciências Agronômicas, Universidade Estadual \\ Paulista, CP 237,CEP 18603-970,Botucatu-SP,E-mail: klar@fca.unesp.br-Pesquisador \\ Cientifico do $\mathrm{CNPq}$
}

\section{RESUMO}

O presente trabalho teve como objetivo verificar o efeito da cobertura plástica de polietileno de baixa densidade (PEBD) sobre a temperatura do ar, umidade relativa do ar, déficit de saturação e tensão de vapor d'água no ar. Pelos resultados encontrados neste trabalho as médias mensais de temperatura do ar no interior da estufa plástica foram superiores em 7,5\%, a umidade relativa do ar em $7 \%$, o déficit de saturação em $34 \%$ e a tensão atual de vapor d'água no ar em $4,7 \%$, em relação aos valores determinados à campo. Observou-se maior efeito da cobertura plástica sobre as temperaturas máximas, as quais levaram as médias mensais a ficar entre 3,8 a $7,8{ }^{\circ} \mathrm{C}$ acima dos valores médios determinados no campo. Os valores médios mensais mínimos de temperatura e umidade relativa do ar entre a estufa e o campo apresentaram menor amplitude de variação que os valores máximos.

UNITERMOS: estufa plástica, temperatura do ar, umidade relativa do ar.

\section{SANTOS, R.F., VILAS BOAS, M.A., KLAR, A.E. AGROMETEOROLOGICAL PARAMETER CHANGES IN A PLASTIC GREENHOUSE}

\section{ABSTRACT}

The aim of this study was to verify the influence of the plastic greenhouse set up in a northsouth main axis orientation on several meteorological parameters in relation to those from outside conditions. The results obtained from this study showed that the means of monthly air temperature were $7.5 \%$; relative humidity, $7.0 \%$; saturation deficit, $34 \%$; and actual water vapour pressure, $4.75 \%$ higher inside the greenhouse than outside it. The maximum air temperature means were 3.8 to $7.8{ }^{\circ} \mathrm{C}$ higher inside the greenhouse than outside it. The minimum air temperature and relative humidity means showed lower range of variation in both environments compared to the one from the maximum values of the same parameters. 
KEYWORDS: air temperature, air relative humidity and vapor pressure.

\section{INTRODUÇÃO}

De acordo com Bot (1992), as exigências de mercado e a proteção ambiental têm despertado interesse de cultivos em ambientes protegidos. O desenvolvimento desta técnica tem crescido no mundo a taxas elevadas (Nelson, 1991), estimando-se um crescimento mundial de aproximadamente $7 \%$ ao ano. Há uma projeção de que a área coberta com estufa no Estado deva dobrar a cada 5 anos (Araújo1995, citado por Medeiros, 1998).

Este impulso da plasticultura gerou grande interesse dos agricultores que procuraram investir nessa nova atividade, porém parte deles sem o conhecimento adequado para o seu desenvolvimento. A escassez de técnicos para atuar na área, a deficiência de resultados de pesquisa sobre o comportamento agronômico de hortaliças sob cultivo protegido são hoje os motivos que mais limitam os avanços da plasticultura na agricultura nacional (Lima et al. 1997).

Além do baixo custo, as estufas plásticas, podem contribuir com um sensível aumento de produção por área, redução da mãode-obra e gastos com insumos, além de propiciar cultivos fora de sua época normal e colheitas precoces, permitindo assim, um abastecimento mais regular do mercado. Com isso, o uso do plástico na agricultura tem sido uma alternativa de proteção a culturas frente às adversidades climáticas.

Com a expansão da atividade, vários problemas surgidos têm sido relatados por agricultores e técnicos envolvidos com esta atividade agrícola. Um dos principais objetivos na produção em ambiente protegido é promover proteção contra fatores adversos do clima, entretanto, a pesquisa científica no Brasil sobre o cultivo em estufa, ainda é muito incipiente (Medeiros, 1998 e Macedo Júnior, 1998).

De acordo com Martinez Garcia (1986), apesar das inúmeras vantagens apresentadas pela estufa plástica, ela se comporta de forma insatisfatória do ponto de vista térmico, uma vez que durante o dia ocorrem temperaturas elevadas, que dificilmente se evitam com a ventilação natural e, à noite, com freqüência, ocorrem temperaturas inferiores às críticas das plantas cultivadas.

Devido à elevada permeabilidade do PEBD, deixando passar de 60 a $90 \%$ da radiação solar de ondas curtas e permitindo a passagem de até $80 \%$ de radiação de ondas longas tem-se, muitas vezes, um efeito contrário ao desejado, ou seja, valores de temperatura no interior das casas de vegetação inferiores aos verificado a céu aberto, fenômeno este conhecido como inversão térmica (De Villele, 1989 e Souza, 1996).

De acordo com Dantas (1997), a temperatura do ar apresenta uma relação das mais complexas com o desenvolvimento das plantas, uma vez que se observam diferentes influências para diferentes processos. Em dias claros observa-se que a temperatura do ar no interior de uma estufa está acima daquela verificada a céu aberto, ao longo de todo o dia, sendo que maiores diferenças ocorrem no período entre 12 e 16 horas, evidenciando o efeito da cobertura plástica sobre as temperaturas máximas (Farias et al., 1993; Dantas, 1997).

Mills et al. (1990) mostram que no verão chuvoso da África do Sul a temperatura máxima, em dias claros, dentro da casa de vegetação, pode atingir mais de $40^{\circ} \mathrm{C}$. Rault (1988) mostrou em seu estudo que em um dia de céu aberto a temperatura máxima atingiu $36^{\circ} \mathrm{C}$ na casa de vegetação com cobertura plástica, enquanto que ao ar livre teve-se $30^{\circ} \mathrm{C}$. Teodoro (1986), em estudo realizado com pimentão em Piracicaba/SP, verificou que a temperatura máxima no interior da casa de vegetação foi de $36,9^{\circ} \mathrm{C}$ e fora da mesma $31,9^{\circ} \mathrm{C}$. Enquanto que as mínimas foram de $18,5^{\circ} \mathrm{C}$ para os dois locais.

O efeito do ambiente protegido sobre a temperatura do ar está relacionado com o balanço de energia. A radiação solar que 
penetra para o interior do ambiente protegido é parcialmente absorvida pelo solo, plantas e objetos, sendo parte convertida em energia térmica (radiação de ondas longas). Esta radiação térmica vai para o espaço e, ao atingir algum material opaco (como deveria ser a cobertura plástica), fica retida neste ambiente, propiciando uma elevação da temperatura do ar. Este fenômeno é conhecido como efeito estufa (Tapia, 1981).

Os valores de umidade relativa do ar no interior de uma estufa são bastante variáveis e estão intimamente relacionados aos valores de temperatura do ar. Prados (1986) verificou que durante o período noturno, com a redução da temperatura, a umidade relativa aumenta no interior da estufa, tornando-se pouco superior à verificada externamente. Este fenômeno ocorre, segundo Tanaka \& Genta (1982), porque durante a noite a umidade relativa aumenta, chegando quase sempre a $100 \%$ logo antes do nascer do sol, devido à queda acentuada de temperatura verificada neste período, no interior da estufa, e à retenção de vapor d'água pela cobertura.

Estudos realizados na região sul do Brasil (Farias et al., 1993), mostram que a umidade relativa no interior de estufas plásticas, em relação ao meio externo, é mais elevada no período noturno, em razão da maior concentração do vapor de água no interior da estufa. Levit \& Gaspar (1988) também observaram que, de maneira geral, no interior de estufas, comparando com o exterior, encontram-se, em média, valores mais elevados de umidade relativa à noite e pela manhã e valores praticamente iguais no período mais quente do dia.

Neste sentido, o presente trabalho tem por objetivo verificar o efeito da cobertura plástica de polietileno de baixa densidade (PEBD) com cultivo de pimentão, sobre a temperatura e umidade relativa do ar, déficit de saturação e tensão de vapor d'água no ar.

\section{MATERIAL E MÉTODOS}

O experimento foi instalado nas dependências do Departamento de Engenharia Rural da Faculdade de Ciências Agronômicas, UNESP, Campus de Botucatu, São Paulo, cujas coordenadas geográficas são: $22^{\circ} 51^{\prime} 03$ ", de latitude Sul, 48 $25^{\prime} 37^{\prime \prime}$ de longitude Oeste e altitude de 786 metros. De acordo com Martins (1989), o clima de região, segundo os critérios adotados por Köppen, é Cfa (clima temperado chuvoso), caracterizado pela existência de quatro ou seis meses consecutivos com temperaturas médias acima de $10^{\circ} \mathrm{C}$, sendo que a temperatura média do mês mais quente é de $22,8^{\circ} \mathrm{C}$ e do mês mais frio de $16,7^{\circ} \mathrm{C}$. A temperatura média anual é de $20,6^{\circ} \mathrm{C}$ e a temperatura média máxima e mínima é de 23,5 e $17,4^{\circ} \mathrm{C}$. O total da precipitação pluvial média é de $1518,8 \mathrm{~mm}$, apresentando um total médio, para o mês mais chuvoso, de $229,5 \mathrm{~mm}$ e de $37,5 \mathrm{~mm}$ para o mês mais seco. A evapotranspiração média anual é de $692 \mathrm{~mm}$.

Foram utilizados os híbridos Elisa, formato quadrado, e Magali R, formato cônico, ambos com aptidão para cultivo protegido e a campo. Da semeadura até o início da colheita, o ciclo foi de aproximadamente 150 dias, com a colheita estendendo-se por cerca de 3 meses.

Para irrigação dentro e fora da estufa, foi utilizado um sistema de gotejamento. Os gotejadores são do tipo longo percurso integrado - labirinto "Tubogotejador Queen Gil", com as seguintes características: (i) pressão recomendada 50 a $70 \mathrm{kPa}$; (ii) vazão a $50 \mathrm{kPa}, 4,0 \mathrm{l} / \mathrm{h}$ por metro linear; (iii) espaçamento entre gotejadores de $30 \mathrm{~cm}$.

$\mathrm{O}$ experimento foi conduzido em uma estufa tipo túnel alto, com dimensões de $27,5 \mathrm{~m}$ de comprimento, $7,5 \mathrm{~m}$ de largura e alturas de pé-direito lateral de $1,70 \mathrm{~m}$ e central de $3 \mathrm{~m}$. A estrutura consta de arcos metálicos de tubos galvanizados sustentados por mourões de concreto. A cobertura foi feita com filme de polietileno aditivado (anti-ultravioleta) com 150 micra de espessura, instalado antes do início do experimento e as laterais foram protegidas com um tela de "sombrite" com 30\% de sombreamento. Nos rodapés, em toda a extensão da estufa, foram instalados filmes plásticos dobrados com $0,2 \mathrm{~m}$ de profundidade e $0,5 \mathrm{~m}$ de altura, a fim de evitar a entrada de água da chuva. Procurou-se posicionar a estufa plástica no sentido norte-sul de modo que 
ficasse perpendicular ao trajeto do sol, para que os canteiros recebessem luminosidade dos dois lados.

Instalou-se, dentro de um abrigo de madeira, no centro da estufa, um termohigrógrafo da marca Dickson (Modelo: THDK) a uma altura de 1,5 metros do solo. Os dados de Campo foram obtidos, na estação meteorológica da Faculdade de Ciências Agronômica, Unesp-Botucatu, SP, localizado a cerca de $500 \mathrm{~m}$ do experimento.

\section{RESULTADOS E DISCUSSÃO}

Apesar de ser viável e apresentar inúmeras vantagens, (efeito guarda chuva, proteção contra insetos, menor velocidade do vento e radiação difusa mais elevada), a estufa plástica se comportou insatisfatoriamente do ponto de vista térmico. Mesmo com a lateral de sobrite para aumentar a ventilação, a temperatura chegou a $41^{\circ} \mathrm{C}$ durante o dia, e à noite, não se conseguiu armazenar calor, em relação ao ambiente externo, chegando à temperatura mínima a $11^{\circ} \mathrm{C}$. Resultados similares foram encontrados por Martinez Garcia (1986) e Farias et al. (1993). De acordo com Prados (1986) e Seemann (1979), este comportamento em abrigos com cobertura de PEBD ocorre porque a temperatura do ar está relacionada com o balanço de energia, que é negativo durante a noite, e que pode ser afetado principalmente pelo volume e tamanho do abrigo, em relação ao campo.

Os valores médios diários, de temperatura, umidade relativa, déficit de saturação e tensão de vapor d'água no ar, observados entre setembro de 1997 à março de 1998, são apresentados na Figura 1.

Analisando-se a amplitude dos resultados observados quanto a temperatura e umidade relativa do ar, ao longo do período, verifica-se que as diferenças entre os valores médios diário, na estufa e no campo, variaram entre 1,26 a $2,89^{\circ} \mathrm{C}$ e 24,5 a $35,0 \%$, respectivamente. Já, a temperatura média diária durante todo o período experimental foi de $25,3^{\circ} \mathrm{C}$ no interior da estufa plástica e $23,4^{\circ} \mathrm{C}$ a campo.

Os valores médios diários de déficit de saturação de vapor d'água no ar e a umidade relativa do ar apresentaram comportamentos idênticos, porém, o inverso, variam, em função da tensão de vapor d'água no ar face à semelhança entre as médias de temperaturas do ar nos dois ambientes. Embora o comportamento dos valores ao longo período da umidade relativa do ar seja inversamente proporcional ao déficit de saturação de vapor, por sua vez, foi diretamente proporcional à temperatura. Isso mostrou que os valores médios diários de umidade relativa do ar no interior da estufa estiveram intimamente relacionados aos valores de temperatura do ar, concordando com Prados (1986).

Desta forma, na estufa, a elevação da temperatura do ar durante o dia, em que o balanço de energia é positivo, reduz os valores de umidade relativa, tornando-os muitas vezes, nas horas mais quente do dia, inferiores aos valores observados a campo.

Em virtude do pequeno volume de ar contido na estufa, a temperatura elevou-se muito em dias de intensa radiação solar. Por isso, para simplificar o manejo e para facilitar a troca de ar do interior da estufa plástica, devido às elevadas temperaturas durante $\mathrm{o}$ dia, seguiram-se as recomendações proposta por Buriol et al. (1993), construiu-se as laterais com telas perfuradas. Segundo este autor, necessitase de muito rigor no controle da ventilação de estufas plásticas para não afetar a produtividade das culturas em regiões tropicais. 

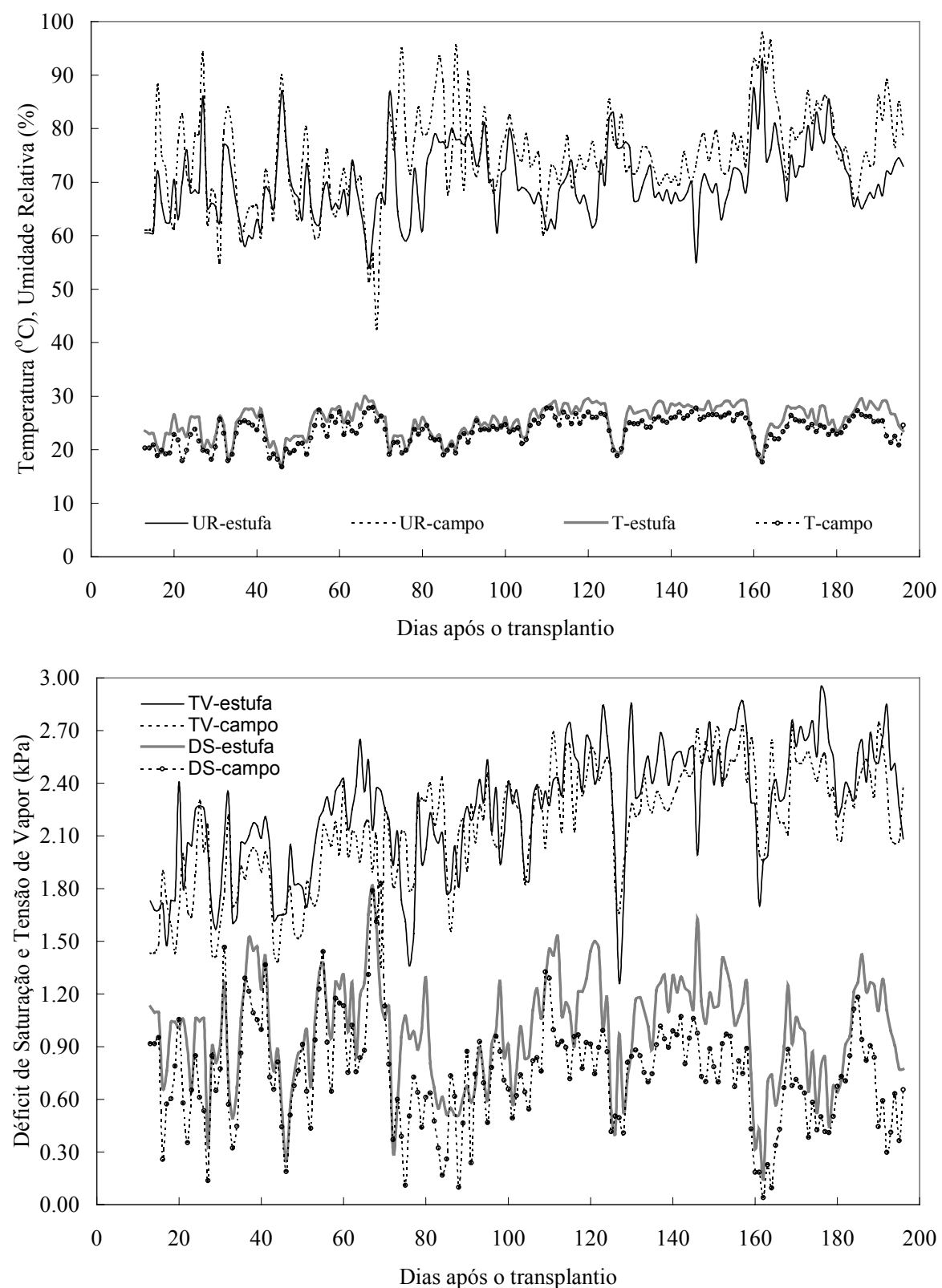

Figura 1. Valores médios diários de temperatura do ar (T), umidade relativa do ar (UR), déficit de saturação do vapor d'água no ar (DS) e tensão atual de vapor d'água no ar (TV) observados na estufa plástica e no campo, cultivados com pimentão.

Observa-se no Quadro 1, que não ocorreram grandes diferenças entre os valores médios mensais de temperatura, umidade realtiva do ar, déficit de saturação e de tensão atual de vapor d'água no ar, verificados interna e externamente, entretanto, foram suficientes para diferenciar de forma significativa $o$ crescimento, desenvolvimento e produção da cultura avaliada.
No período estudado (setembro a fevereiro), a diferença entre os valores médios mensais de temperatura do ar, entre a estufa e o campo, foi de $1,93^{\circ} \mathrm{C}$. Já Farias et al. (1993), encontraram em Pelotas RS, diferença de $0,85^{\circ} \mathrm{C}$ entre o ambiente externo e interno à estufa plástica entre no período estudado de setembro a janeiro.

Verifica-se ainda no Quadro 1 que, a 
média mensal do período da temperatura do ar na estufa foi superior em $7,5 \%$ ao campo. Similarmente, o valor de umidade. relativa do ar foi superior ao campo em 7,0\%. De acordo com o resultado obtido por Martins et al.
(1994), existe um pequeno efeito da cobertura plástica sobre a temperatura e umidade relativa do ar em estufa tipo túnel, quando as mesmas permanecem com as laterais abertas no verão.

Quadro 1. Valores médios mensais de temperatura do ar, umidade relativa do ar, déficit de saturação do vapor d'água no ar e tensão atual de vapor d'água no ar (T.A.V.), observados na estufa e no campo de setembro de 1997 a março de 1998 em Botucatu, SP.

\begin{tabular}{lcccccccc}
\hline Mês & \multicolumn{2}{c}{ Temperatura } & \multicolumn{3}{c}{ Umidade Relativa } & \multicolumn{2}{c}{ Déficit Saturação } & \multicolumn{2}{c}{ T.A.V. água no ar } \\
\hline & \multicolumn{3}{c}{$\left({ }^{\circ} \mathrm{C}\right)$} & \multicolumn{2}{c}{$(\%)$} & \multicolumn{2}{c}{$(\mathrm{kPa})$} & \multicolumn{2}{c}{$(\mathrm{kPa})$} \\
& Estufa & Campo & Estufa & Campo & Estufa & Campo & Estufa & Campo \\
Setembro & 23,57 & 20,68 & 66,32 & 71,64 & 0,97 & 0,69 & 1,92 & 1,73 \\
Outubro & 23,47 & 21,73 & 68,14 & 69,95 & 0,95 & 0,81 & 1,94 & 1,79 \\
Novembro & 24,72 & 23,29 & 68,720 & 73,48 & 1,00 & 0,79 & 2,12 & 2,06 \\
Dezembro & 25,59 & 24,33 & 70,79 & 75,11 & 0,97 & 0,77 & 2,29 & 2,25 \\
Janeiro & 27,04 & 25,15 & 70,27 & 74,15 & 1,11 & 0,83 & 2,45 & 2,35 \\
Fevereiro & 26,23 & 24,27 & 74,64 & 81,86 & 0,89 & 0,57 & 2,51 & 2,45 \\
Março & 26,66 & 24,34 & 71,61 & 77,61 & 1,00 & 0,69 & 2,47 & 2,33 \\
Média & 25,33 & 23,40 & 69,89 & 74,83 & 0,98 & 0,73 & 2,24 & 2,14 \\
\hline
\end{tabular}

Na Figura 2 são apresentados os valores médios diários das temperaturas e umidades relativas do ar, máximas e mínimas, na estufa plástica e no campo. Verifica-se que, ao longo de todo o experimento, as médias das temperaturas máximas do ar foram maiores no interior da estufa, diferindo em média, entre os locais, em $5,1^{\circ} \mathrm{C}$. Também os estudos realizados com pimentão, Teodoro \& Oliveira (1993), encontraram a diferenças médias diárias entre túnel plástico e campo de $5,1^{\circ} \mathrm{C}$. Observa-se ainda na Figura 2, que o comportamento das curvas de temperaturas mínimas diárias, ao longo do período estudado, são similares entre os locais. Em estudos realizados a campo e em estufa plástica, Urban (1972) concluiu que, à noite, as temperaturas mínimas permaneceram iguais, dentro e fora da casa de vegetação. Trabalhando também com pimentão, os mesmos resultados foram encontrados por Teodoro \& Oliveira (1993), onde as temperaturas mínimas registradas no interior da estufa plástica, foram idênticas aos valores determinados a campo.

O valor mais elevado diário de temperatura máxima do ar diária determinada ao longo do período foi de $33,8{ }^{\circ} \mathrm{C}$ no campo e $41{ }^{\circ} \mathrm{C}$ no interior da estufa plástica, ocorrido ambas no final da estação de primavera que, para a região de Botucatu, SP, também se considera o início de estação chuvosa. Embora em outro continente, estes resultados também concordam com os de Mills et al. (1990), onde afirmam que na estação de verão, na África do Sul, com chuva, as temperaturas máximas em dias claros, dentro da casa de vegetação, podem atingir a valores maiores que $40{ }^{\circ} \mathrm{C}$. As diferenças entre as temperaturas máximas nos dois ambientes foram de $5,07^{\circ} \mathrm{C}$, enquanto que as diferenças entre as temperaturas mínimas foram de apenas $1,22^{\circ} \mathrm{C}$, concordando com os resultados encontrados por Segovia et al. 1997.

Analisando-se o comportamento das temperaturas nos dois ambientes, observou-se que o efeito da cobertura plástica é mais sensível sobre as temperaturas máximas. Esse mesmo comportamento foi constatado por outros pesquisadores (De Villele 1989; Farias, 1993), que atribuíram esse fato à íntima relação entre a temperatura do ar, a radiação solar e o menor volume de ar a ser aquecido. 

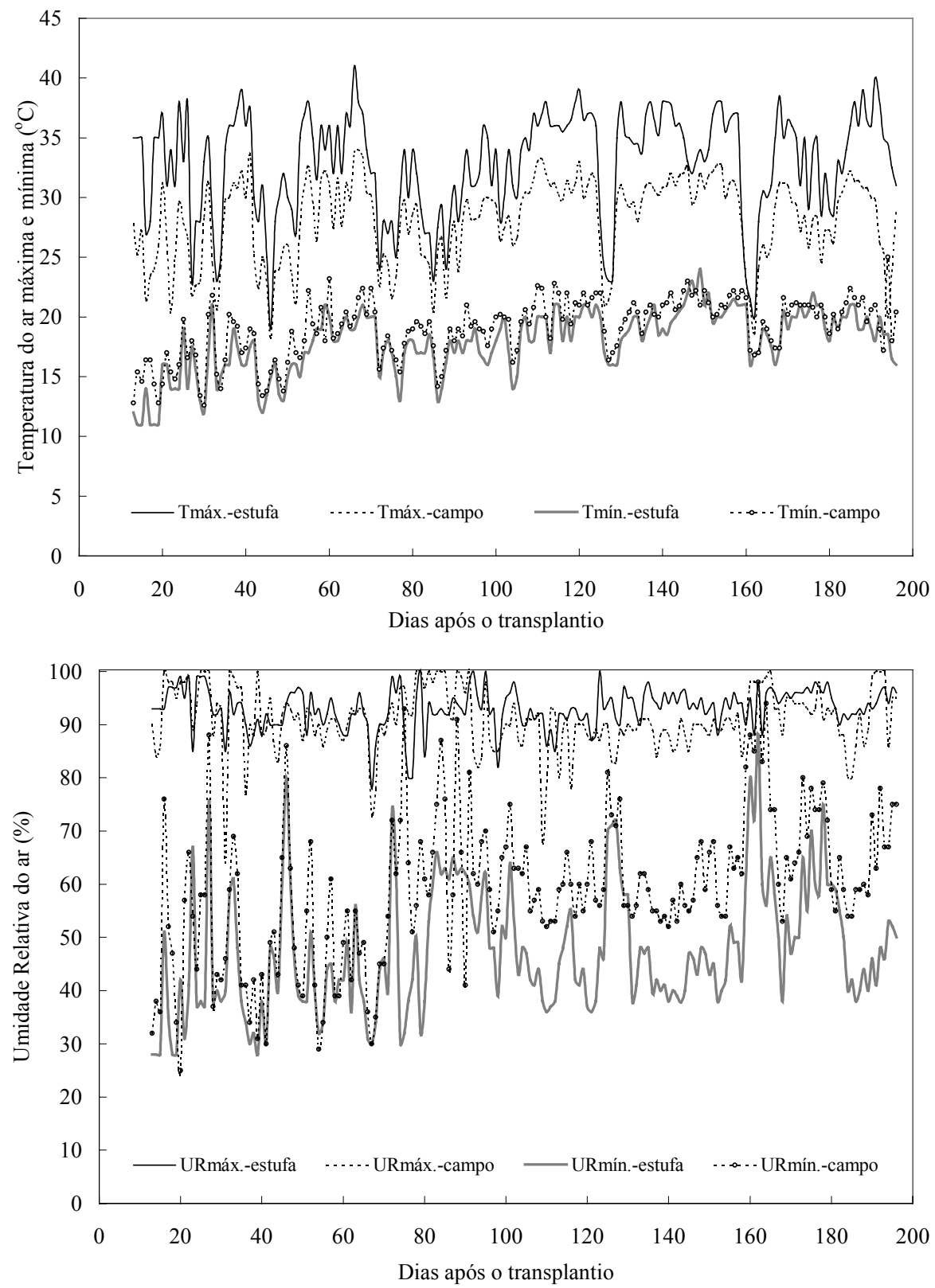

Figura 2. Valores médios diários de temperatura do ar máxima (Tmáx.) mínima (Tmín.), umidade relativa do ar máxima (URmáx.) e mínima (URmín.), observados na estufa plástica e no campo cultivado com híbridos de pimentão submetidos a diferentes doses de $\mathrm{N}+\mathrm{K}$ em Botucatu, SP. de Setembro de 1997 a Março de 1998.

Porém, com relação às temperaturas mínimas durante a noite, o efeito da cobertura não segue o mesmo comportamento, pois o PEBD deixa passar parte da radiação térmica emitida pelos corpos presentes no interior da estufa e desta forma não permite um acentuado "efeito estufa" (Robledo \& Martin, 1981; Tapia, 1981). Tal efeito manifestou-se, implicando em valores inferiores de temperatura mínima no interior na estufa, quando relacionado ao ambiente externo.

Além das perdas de radiação térmica, a estufa também perde energia por processos de condução e convecção através de sua cobertura, pelas aberturas existentes e pelo fluxo através do solo (Martinez Garcia, 1978). A céu aberto, 
também há grandes perdas de radiação térmica, porém os movimentos horizontais e verticais de massa de ar podem transportar calor, aquecendo o ambiente externo via mistura de camadas de ar, o que não ocorre no interior da estufa. Assim, é possível a ocorrência de temperaturas internas inferiores às verificadas externamente, concordando com os resultados encontrados por Farias et al. (1993).

As diferenças entre as temperaturas mínimas diárias na estufa e no campo variaram entre $-3,0$ a $6,5^{\circ} \mathrm{C}$ e as diferenças entre as temperaturas máximas na estufa e no campo variaram entre $-0,4$ a $14,5^{\circ} \mathrm{C}$. Observou-se que as maiores diferenças de temperaturas máximas do ar ocorreram entre 13 e 17 horas, o que, mais uma, vez, evidencia o maior efeito da cobertura plástica sobre as temperaturas máximas, concordando com Martin et al. (1982), Tanaka \& Genta (1983) e Farias et al. (1993).

Portanto, não se verificou nenhum comportamento anormal dos valores de temperaturas mínimas diárias no período entre as diferenças observadas nos dois ambientes. A noite, como não há incidência de radiação solar e a estufa perde energia, a temperatura do ar no ambiente interno apresentou-se inferior ao campo.

Segundo Martinez Garcia (1978), a diferença de temperatura entre os dois ambientes provoca maior condensação de vapor d'água sobre a parte interna da cobertura, o que, também, pode ter contribuído para o aumento da tensão de vapor d'água interno. Porém, apesar das diferenças existentes entre a umidade relativa na tensão de vapor nos dois ambientes, levando em consideração as diferenças de temperatura, obteve-se valores médios de umidade relativa do ar, no interior da estufa mais baixos que os observados a campo, exceto nos dias chuvosos. Estes resultados são similares aos encontrados por Alves \& Klar (1996) e Farias et al. (1993), porém, discordam dos resultados de Dantas (1997).

Os valores diários de umidade relativa do ar menores no interior da estufa do que no campo, discordam de trabalhos realizados em estufas plásticas no inverno. Porém, esses resultados se devem ao comportamento das temperaturas máximas alcançadas no interior da estufa em dias de céu aberto, principalmente em meses de temperatura mais elevada.

Ao longo de todo o experimento, os valores médios diários de umidade relativa mínima, foram, de modo geral, maiores a céu aberto, variando de 29 a $98 \%$, do que no interior da estufa plástica, onde ficaram entre 28 a $88 \%$. Este fato pode ser explicado, segundo Martinez Garcia (1986) e Prados (1986) pela dependência da umidade relativa do ar com a temperatura, cujos maiores valores são atingidos, em geral, no período diurno, permitindo maior tensão de saturação de vapor d'água. Como a lateral da estufa foi com sombrite, a tensão de vapor d'água interna não ficou muito acima da verificada externamente. Cabe salientar, que a radiação solar incidente no interior da estufa é parcialmente absorvida pelo solo, plantas e atmosfera local, sendo parte desta, convertida em energia térmica. Uma parcela dessa radiação, segundo Tapia (1981), é reirradiada e, ao atingir a cobertura plástica, fica retida neste ambiente, proporcionando elevação da temperatura do ar internamente.

Assim, a elevação da temperatura do ar durante o período diurno no interior da estufa, contribuiu para os menores valores de umidade relativa, já a queda de temperatura no período noturno contribuiu para os maiores valores de umidade relativa do ar no interior da estufa, concordando com os resultados encontrados por Prados (1986) e Farias et al. (1993). A elevação nos valores de umidade relativa no interior da estufa superior aos valores verificado exteriormente ocorre segundo Tanaka \& Genta (1982), porque durante a noite a umidade relativa chega atingir $100 \%$, próximo do nascer do sol, devido à queda acentuada de temperatura verificada neste período no interior da estufa e a retenção de vapor d'água pela cobertura. Comparando com o ambiente exterior, Levit \& Gaspar (1988) observaram que, de maneira geral, no interior da estufa, encontram-se, em média, valores mais elevados de umidade relativa à noite e pela manhã e, valores praticamente iguais no período mais quente do dia, em torno de 14 e 15 horas.

Os valores extremos de temperatura e umidade relativa do ar mantiveram-se numa faixa adequada para o cultivo do pimentão concordando com Pereira (1990) e Sganzerla 
(1995). Entretanto, as mais elevadas temperaturas nos meses de verão e os mais baixos valores de umidade relativa do ar, coincidiram com a época reprodutiva da cultura, provocando abortamento de flores, principalmente na estufa. Deste modo, é de fundamental importância o manejo desses dois parâmetros no interior da estufa plástica, para se evitar a queda de flores e frutos.

Verifica-se no Quadro 6 que, as diferenças térmicas médias entre as temperaturas máximas e mínimas, dentro de cada ambiente, durante todo o ciclo da cultura, foi de $15,33^{\circ} \mathrm{C}$ na estufa e $9,04^{\circ} \mathrm{C}$ no campo, uma diferença de $59 \%$ entre os ambientes. Já para os valores extremos, de umidade relativa do ar, a diferença foi de 46,76 pontos percentuais na estufa contra 32,41 pontos percentuais no campo, uma diferença de $69 \%$ entre os ambientes. Estes resultados mostram que a amplitude de variação dos valores extremos, tanto de temperatura do ar como da umidade relativa, foram maiores na estufa plástica que no campo.

As diferenças térmicas entre os ambientes para os valores médios no final do período de temperatura do ar mínimas e máximas foram, respectivamente, de $1,22^{\circ} \mathrm{C}$ menor e $5,07^{\circ} \mathrm{C}$ maior na estufa plástica. Portanto, verifica-se que os valores médios mensais de temperaturas mínimas do ar no campo foram superiores aos valores encontrados no ambiente protegido. Espera-se que, o ambiente protegido armazene mais calor que o ambiente externo durante a noite, entretanto, segundo De Villele (1989), devido à elevada permeabilidade do PEBD e à radiação de ondas longas tem-se, muitas vezes, um efeito contrário ao desejado, ou seja, valores de temperatura no interior das estufas inferiores aos verificados a campo, fenômeno este conhecido como "inversão térmica". Também, de acordo com Tanaka \& Genta (1982), durante o dia as perdas de calor que ocorrem através da cobertura e laterais da estufa são compensadas pela radiação solar incidente, as temperaturas podem se elevar no ambiente interno principalmente devido à redução da ação dos ventos no resfriamento do ambiente. Porém, à noite, não há incidência de radiação solar e a estufa continua perdendo energia, levando, às vezes porém, a temperaturas do ar no interior da estufa plástica a valores inferiores ao campo, conforme verificado na comparação das temperaturas mínimas no Quadro 2, concordando com e Martinez Garcia, (1986).

Já as diferenças no final do período para os valores extremos de umidade relativa do ar foram de $12,15 \%$ menor na estufa para as mínimas e 2,2\% maior, também, na estufa para as máximas. Estes resultados confirmam que a estufa com cobertura PEBD alterou acentuadamente os valores extemos de umidade relativa do ar, assim como os de temperatura, interagindo diretamente com as condições atmosféricas do ambiente externo.

Quadro 2. Valores médios mensais extremos de temperatura do ar e umidade relativa do ar, observadas na estufa e no campo de setembro de 1997 a março de 1998 em Botucatu, SP.

\begin{tabular}{lcccccccc}
\hline & \multicolumn{4}{c}{ Temperatura $\left({ }^{\circ} \mathrm{C}\right)$} & \multicolumn{3}{c}{ Umidade Relativa (\%) } \\
\hline Mês & \multicolumn{9}{c}{ Estufa } & \multicolumn{3}{c}{ A campo } & \multicolumn{2}{c}{ estufa } & \multicolumn{2}{c}{ A campo } \\
& Mínimo & Máximo & Mínimo & Máximo & Mínimo & Máximo & Mínimo & Máximo \\
& 13,43 & 33,71 & 15,49 & 25,87 & 37,07 & 95,57 & 48,36 & 94,93 \\
Setembro & 15,81 & 31,11 & 17,04 & 26,42 & 44,43 & 92,06 & 49,39 & 90,52 \\
Outubro & 17,84 & 31,59 & 18,82 & 27,76 & 46,53 & 90,90 & 56,10 & 90,87 \\
Novembro & 18,05 & 33,10 & 19,64 & 29,01 & 49,13 & 92,45 & 61,52 & 88,71 \\
Dezembro & 19,66 & 34,42 & 20,56 & 29,74 & 46,82 & 93,73 & 60,00 & 88,29 \\
Janeiro & 19,613 &
\end{tabular}




\begin{tabular}{lllllllll}
\hline Fevereiro & 19,68 & 32,79 & 20,18 & 28,36 & 54,89 & 94,39 & 70,60 & 93,11 \\
Março & 19,13 & 34,18 & 20,41 & 28,27 & 49,42 & 93,95 & 64,79 & 91,21 \\
Média & 17,66 & 32,99 & 18,88 & 27,92 & 46,53 & 93,29 & 58,68 & 91,09 \\
\hline
\end{tabular}

Analisando-se o Quadro 2, com relação ao período avaliado, observa-se que o valor médio no final do período da umidade relativa do ar máxima, foi apenas pouco maior na estufa em relação ao campo. Este mesmo comportamento da umidade relativa máxima foi observado por Farias et al. (1993) em Pelotas, RS, cujo valor assumiu $97,4 \%$ para a estufa e 95,2 para o campo.

Como a estufa ficou parcialmente aberta, em função da tela de sombrite, estes valores mais elevados de umidade relativa do ar no interior da estufa ocorreram, em geral, durante a noite, devido ao aumento da retenção de vapor d'água neste ambiente uma vez que o filme plástico é praticamente impermeável ao vapor d'água (Robledo \& Martin, 1981).

Os valores médios mensais de temperatura máxima encontrada foram de $32,99^{\circ} \mathrm{C}$ na estufa plástica e $27,92^{\circ} \mathrm{C}$ no campo, já os valores médios de temperaturas mínimas foram de 17,66 e 18,88 respectivamente no ambiente interno da estufa plástica e externo. Em estudos realizados com pimentão em Piracicaba/SP, encontraram-se valores médios de temperaturas máximas no interior da estufa de $36,9^{\circ} \mathrm{C}$ e a campo de $31,9^{\circ} \mathrm{C}$, enquanto que a média das mínimas foi de $18,5^{\circ} \mathrm{C}$ para os dois locais (Teodoro, 1986).

\section{CONCLUSÕES}

No comportamento dos parâmetros meteorológicos, em geral, a média da temperatura do ar mensal na estufa foi superior em 7,5\% a do campo. Similarmente, o valor da umidade relativa do ar foi superior ao campo em 7,0\%, o déficit de saturação em $34 \%$ e a tensão atual de vapor d'água no ar em $4,7 \%$. As temperaturas máximas, médias mensais ficaram entre 3,8 a $7,8{ }^{\circ} \mathrm{C}$ acima dos valores médios determinados no campo. Os valores médios mensais mínimos de temperatura e umidade relativa do ar, entre a estufa e o campo, apresentaram menor amplitude de variação que os valores máximos.

\section{REFERÊNCIAS BIBLIOGRÁFICAS}

\author{
ALVES, D. R. B. O.; KLAR, A. E. \\ Comparação de métodos para estimar \\ evapotranspiração de referência em túnel de \\ plástico. Irriga, Botucatu, v. 1, n. 2 p. 26-34, \\ 1996. \\ BOT, G. P. A. Greenhouse growing: outlook
} 2000. Acta Horticulture, Leuven, v. 304, n. 1, p. 43-47, 1992.

BURIOL, G. A. et al. Modificações na temperatura mínima do ar causada por estufas de polietileno transparente de baixa densidade.

Revista Brasileira de Agrometeorologia,

Santa Maria, v. 1, n. 1, p. 43-49, 1993.

DANTAS, R.T. Parâmetros meteorológicos e análise de crescimento da alface (Lactuca sativa, L.) em ambientes natural e protegido. 1997. 109 f. Tese (Doutorado em

Agronomia/Energia na Agricultura) -

Faculdade de Ciências Agronômicas.

Universidade Estadual Paulista, Botucatu, 1997.

VILlele, O. de Probleme de

bioclimatologie estimation des besoins en eau des culture de serre. Paris: Commission

Economique pour Éurope/Comité des

Problemes Agricoles, 1989. 16 p. (Seminaries, Nations Unites).

FARIAS, J. R. B. et al. Alterações na temperatura e umidade relativa do ar provocadas pelo uso de estufa plástica. Revista Brasileira de Agrometeorologia, Santa Maria, v. 1, n. 1, p. 51-62, 1993.

LEVIT, G. J., GASPAR, R. Energy budget for greenhouse in humid temperature climate.

Agricuture and Forest Meteorology, New

York, v. 44, n. 2, p. 241-254, 1988. 
LIMA, M. S. de et al. Avaliação de diferentes variedades de tomate (Lycopersicon esculentum Mill.) cultivadas sob estufas, em dois sistemas de condução. In: CONGRESSO BRASILEIRO DE OLERICULTURA, 37., 1997, Manaus.

Resumo... Brasília: Sociedade de Olericultura do Brasil/Instituto Nacional de Pesquisas da Amazônia, 1987. (Resumo, 137).

MACEDO JUNIOR, E. K. Crescimento e produtividade de pepino (Cucumis sativus $\mathrm{L}$.) enxertado e não enxertado, submetido à adubação convencional em cobertura e fertirrigação, em cultivo protegido. 1998. 129 f. Tese (Doutorado em Agronomia - Irrigação e Drenagem) - Faculdade de Ciências

Agronômicas, Universidade Estadual Paulista, Botucatu, 1998.

MARTINEZ GARCIA, P. F. Características climáticas de los invernaderos de plástico. Madrid: Instituto Nacional de Investigaciones Agrarias, 1978. 43 p. (Hoja Técnica, 19). MARTINEZ GARCIA, P. F. La regulación de las condiciones del ambiente en los cultivos protegidos. In: FERIA TECNICA INTERNATIONAL DE LA MAQUINARIA AGRÍCOLA, 1986, Zaragoza. Anales... Zaragoza: Asociación Nacional de Ingenieros Agrónomos, 1986. p. 135-147.

MARTINS, D. Clima da região de Botucatu. In: ENCONTRO DE ESTUDO SOBRE A AGROPECUÁRIA NA REGIÃO DE BUTUCATU, 1989, Botucatu. Anais... Botucatu: Faculdade de Ciências Agronômicas - Universidade Estadual Paulista, 1989. p. 8-19. MARTINS, G. et al. Influência da casa de vegetação nos aspectos climáticos e em épocas de verão chuvoso. Horticultura Brasileira, Brasília, v. 12, n. 2, p. 131-134, 1994. MEDEIROS, J. F. Manejo da água de irrigação salina em estufa cultivada com pimentão. 1998. 152 f, Tese (Doutorado em Irrigação e Drenagem) - Escola Superior de Agricultura "Luiz de Queiroz". Universidade de São Paulo, Piracicaba, 1998.

MILLS, P. J. W., SMITH, I. E., MARAIS, G. A greenhouse design for a cool subtropical climate with mild winters based on microclimatic measurements of protected environments. Acta Horticulture, Leuven, v. 281, n. 1, p. 83-94, 1990.
NELSON, P. V. Greenhouse: operation and management. 4. ed. Englewood Cliffs: Prentice Hall, 1991. 612 p.

PRADOS, N. C. Contribuitión al estudio de los cultivos enarenados en Almería: necesidades hídricas y extracción de nutrientes del cultivo de tomate de crecimiento indeterminado en abrigo de polietileno. 1986. 195 f. Tese (Doctorado em Fitotecnia) - Caja Rural Provincial, Almería, 1986.

RAULT, P. A. Protected crops in humid tropical regions. Acta Horticulture, Leuven, v. 230, n. 3, p. 565-572, 1988.

ROBLEDO DE PEDRO, F.; MARTINS

VICENTE, L. Aplicación de los plásticos en la agricultura. Madrid: Ediciones Mundi-Prensa, $1981.553 \mathrm{p}$.

SEEMANN, J. Greenhouse climate. In:

SEEMANN, J. et al. Agrometeorology. Berlin: Heidelberg: Springer-Verlag, 1979. p. 165-178. SEGOVIA, J. F. O. et al. Comparação do crescimento e desenvolvimento da alface (Lactuca sativa L.) no interior e exterior de uma estufa plástica de polietileno em Santa Maria,

RS. Ciência Rural, Santa Maria, v. 27, n. 1, p. 37-41, 1997.

SGANZERLA, E, Nova Agricultura: a fascinante arte de cultivar com plástico. 5. ed. Guaíba: Agropecuária, 1995. 342 p.

SOUZA, J. L. Saldo radiômetro com termopilha de filme fino e aplicação no balanço de radiação de energia em cultivo de feijão vagem, (Phaseolus vulgaris $L$.) com e sem cobertura de polietileno. 1996. $172 \mathrm{f}$. Tese (Doutorado em Agronomia/ Energia na Agricultura.) - Faculdade de Ciências Agronômica, Universidade Estadual Paulista, Botucatu, 1996.

TANAKA, M.; GENTA, H. Control del medio ambiente bajo invernadero y túnel plástico. Salto: Estación Experimental de Citricultura, 1982. $61 \mathrm{p}$.

TAPIA, G. J. Filmes técnicos para invernaderos. Revista de Plásticos Modernos, Madri, v. 295, n. 1, p. 75-82, 1981. TEODORO, R. E. F. Efeito da irrigação no crescimento e produção do pimentão (Capsicum annuum L.) Conduzido em casa de vegetação e em condições de campo. 1986. 67 f. Dissertação (Mestrado em Irrigação e 
Drenagem) - Escola Superior de Agricultura "Luiz de Queiroz", Universidade de São Paulo, Piracicaba, 1986.

TEODORO, R. E. F. et al. Efeito da irrigação no crescimento e produção do pimentão (Capsicum annuum $L$,) em casa de vegetação.

Ciencia Agrícola, Piracicaba, v. 50, n. 2, p.
237-243, 1993.

URBAN, L. Temperature und feuichtigkeytsverlauf eines folien -

Gewächshauses. Gemüse, (S.I.), v. 7, n. 7, p. 1990-1991, 1971. 